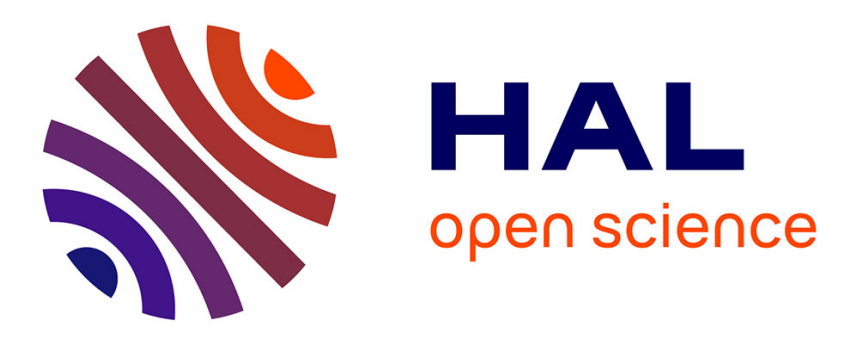

\title{
Field induced transitions in smectic a phases
}

\author{
M. Goscianski, L. Leger, A. Mircea-Roussel
}

\section{To cite this version:}

M. Goscianski, L. Leger, A. Mircea-Roussel. Field induced transitions in smectic a phases. Journal de Physique Lettres, 1975, 36 (12), pp.313-316. 10.1051/jphyslet:019750036012031300 . jpa-00231217

\section{HAL Id: jpa-00231217 https://hal.science/jpa-00231217}

Submitted on 1 Jan 1975

HAL is a multi-disciplinary open access archive for the deposit and dissemination of scientific research documents, whether they are published or not. The documents may come from teaching and research institutions in France or abroad, or from public or private research centers.
L'archive ouverte pluridisciplinaire HAL, est destinée au dépôt et à la diffusion de documents scientifiques de niveau recherche, publiés ou non, émanant des établissements d'enseignement et de recherche français ou étrangers, des laboratoires publics ou privés. 
Classification

Physics Abstracts

7.130

\title{
FIELD INDUCED TRANSITIONS IN SMECTIC A PHASES $\left(^{*}\right)$
}

\author{
M. GOSCIANSKI, L. LEGER (**) and A. MIRCEA-ROUSSEL
}

Laboratoires d'Electronique et de Physique Appliquée, 3, avenue Descartes, 94450 Limeil-Brévannes, France

(Reçu le 16 juillet 1975, révisé le 10 septembre 1975, accepté le 29 septembre 1975)

Résumé. - Des transitions de l'orientation moléculaire induites par un champ électrique ou magnétique ont été mises en évidence dans différents composés smectiques $\mathrm{A}$.

Deux régimes de distorsion ont été observés :

- près de la transition smectique $A \rightarrow$ nématique, une distorsion périodique, de vecteur d'onde perpendiculaire au plan (n, $\left.\mathbf{n}_{0}\right)$;

- à plus basse température, deux réseaux périodiques de défauts, perpendiculaires au plan (n, $\left.\mathbf{n}_{0}\right)$ permettent le pliage des couches.

Les dépendances du champ seuil en fonction de l'épaisseur de l'échantillon et de la température, et la variation de l'angle de basculement des molécules en fonction du champ appliqué sont discutées pour le second régime de distorsion.

Abstract. - Observations of electric and magnetic field induced transitions of the molecular orientation in smectics A are presented.

Two regimes of distortion can be distinguished :

- close to the nematic/smectic A transition, a periodic distortion appears with a wave vector normal to the plane $\left(\mathbf{n}, \mathbf{n}_{0}\right)$.

- for lower temperatures, two periodic arrays of defects, normal to the plane $\left(\mathbf{n}, \mathbf{n}_{0}\right)$, allow for the folding of the smectic layers.

The dependence of threshold field versus sample thickness and temperature, and the variation of the tilt angle of the molecules versus applied field are discussed for the second regime of distortion.

1. Introduction. - In a nematic slab, the competition between the alignment induced by the limiting planes of the sample, and an applied magnetic or electrical field has been extensively studied, since Freedericksz' work in 1933 [1].

In a smectic A slab, these phenomena have only been investigated theoretically :

- in the case of homeotropic boundary conditions, a transition of undulation of the smectic layers is predicted, above a threshold

$$
H_{\mathrm{c}}^{2}=\frac{2 \pi}{\chi_{\mathrm{a}}} \frac{\left(\bar{B} K_{1}\right)^{1 / 2}}{d}
$$

( $d$ is the sample thickness $\chi_{\mathrm{a}}$ the anisotropic part of magnetic susceptibility, $K_{1}$ the splay elastic constant, and $\bar{B}$ the elastic modulus of the layers) [2];

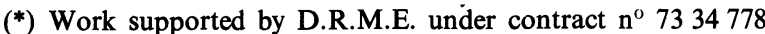
004807501 .

(**) Permanent address : Laboratoire de Physique des Solides, Bât. 510, 91405 Orsay, France.
- in the case of planar boundary conditions a splay distortion is predicted, above a threshold :

$$
H_{\mathrm{c}}=\frac{\pi}{d}\left(\frac{K_{1}}{\chi_{\mathrm{a}}}\right)^{1 / 2} \quad[3] \text {. }
$$

However, owing to the quasi-incompressibility of the smectic layers, the amplitude of the distortion must remain very small in both cases, and the transitions should not be visible : they are ghost transitions [2, 3].

For higher fields, a visible transition is predicted by Parodi, the folding of the smectic layers being allowed through the nucleation of a periodic array of defects [4].

In this paper we present experimental evidence of that second kind of transition for different smectic A compounds submitted to an electrical high $\left({ }^{1}\right)$ frequency field. We call it Parodi type transition.

( $\left.{ }^{1}\right)$ The frequency is chosen sufficiently high $(2 \mathrm{kHz}$ to $5 \mathrm{kHz})$ to avoid spurious electrohydrodynamic instabilities (M. Goscianski, Philips Res. Rep. Supp. 30 (1975) 37). 
We also describe a completely different regime of distortion which exists in a very narrow temperature range, just below the nematic to smectic $\mathrm{A}$ transition temperature.

2. Experimental conditions. - The experiments have been performed on various compounds [5].

For planar to homeotropic transitions, we have used three compounds with a positive dielectric anisotropy $\left(\varepsilon_{\mathrm{a}}\right)$ :

- 4 cyano-4'-n. octyloxybiphenyl (M24)

crystal $\underset{54^{\circ} \mathrm{C}}{\rightleftharpoons}$ smectic $A \underset{67^{\circ} \mathrm{C}}{\underset{\rightleftharpoons}{\rightleftharpoons}}$ nematic $\underset{80^{\circ} \mathrm{C}}{\rightleftharpoons}$ isotropic $\varepsilon_{\mathrm{a}}=8.5$ at $66^{\circ} \mathrm{C}$.

- 4 cyano-4'-n. octylbiphenyl (K24)

crystal $\underset{21^{\circ} \mathrm{C}}{\rightleftharpoons}$ smectic $A \underset{32^{\circ} \mathrm{C}}{\underset{\rightleftharpoons}{\rightleftharpoons}}$ nematic $\underset{40^{\circ} \mathrm{C}}{\rightleftharpoons}$ isotropic $\varepsilon_{\mathrm{a}}=7.5$ at $31^{\circ} \mathrm{C}$.

- 4 - cyanobenzylidene $-4^{\prime}-n$. octyloxyaniline (CBOOA)

$$
\begin{gathered}
\text { crystal } \underset{73^{\circ} \mathrm{C}}{\rightleftharpoons} \text { smectic } A \underset{84^{\circ} \mathrm{C}}{\rightleftharpoons} \text { nematic } \underset{109^{\circ} \mathrm{C}}{\rightleftharpoons} \text { isotropic } \\
\varepsilon_{\mathrm{a}}=7.6 \text { at } 80^{\circ} \mathrm{C} .
\end{gathered}
$$

For homeotropic to planar transition, we have used : 4- $n$. butoxybenzylidene-4'-n. octylaniline (40.8) :

$$
\begin{gathered}
\text { crystal } \underset{31.1^{\circ} \mathrm{C}}{\rightleftharpoons} \text { smectic } \mathrm{B} \underset{48{ }^{\circ} \mathrm{C}}{\rightleftharpoons} \text { smectic A } \\
\underset{62.5^{\circ} \mathrm{C}}{\rightleftharpoons} \text { nematic } \underset{77.8^{\circ} \mathrm{C}}{\rightleftharpoons} \text { isotropic } \\
\varepsilon_{\mathrm{a}}=-0.33 \text { at } 60^{\circ} \mathrm{C} .\left(^{2}\right)
\end{gathered}
$$

The experimental arrangement has been extensively described elsewhere [6]. The sample, sandwiched between two nesa coated glass plates separated by 20-290 $\mu \mathrm{m}$ mylar spacers, is inserted into an electronically regulated oven, and is observed through a polarizing microscope. The planar anchoring for the M24, K24 and CBOOA samples is obtained by evaporating silicon monoxide under oblique incidence [7] onto the electrodes. The homeotropic anchoring for the 40.8 sample is reached by coating the electrodes with a thin layer of cetyltrimethylammoniumbromide [8].

3. Parodi type transition. - If we apply an increasing electrical field on a planar M24, K24 or CBOOA sample, the orientation of the molecules remains unchanged, as checked by conoscopic observations, up to a threshold for which two periodic arrays of defects appear, each one being located near one electrode. One of these arrays is shown on figure $1 a$ : the lines are normal to the rest direction of orientation of the molecules, $\mathbf{n}_{0}$, and are not visible with incoming

( ${ }^{2}$ Mircea-Roussel, A. Unpublished results. light polarized normal to $\mathbf{n}_{\mathbf{0}}$. The aspect of the sample above threshold is similar to the one observed by C. Williams when applying a shear on planar CBOOA samples [9].

Figure $1 b$ shows the similar transition in the case of a homeotropic 40.8 sample : since in this case no preferred direction is imposed in the plane of the slab, the arrays of defects take the form of concentric rings around singular points which play the role of umbilics
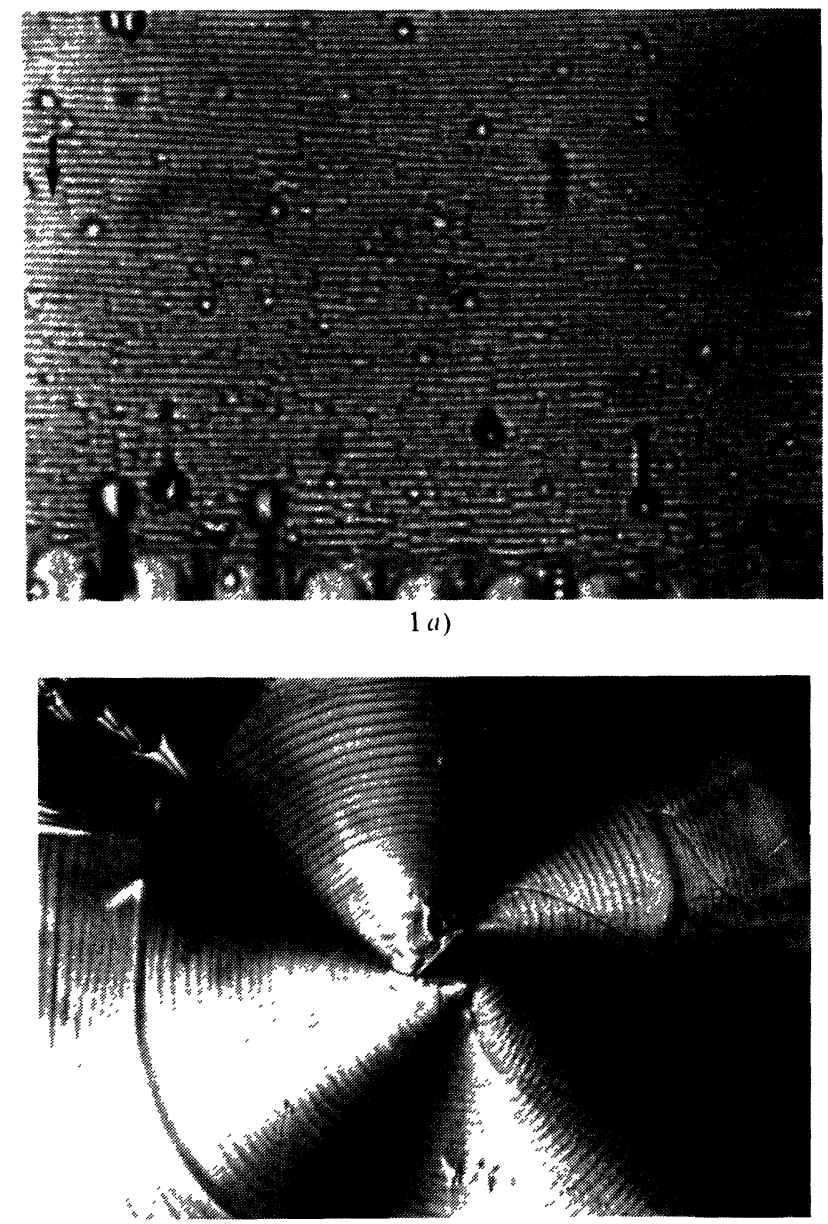

$1 h)$

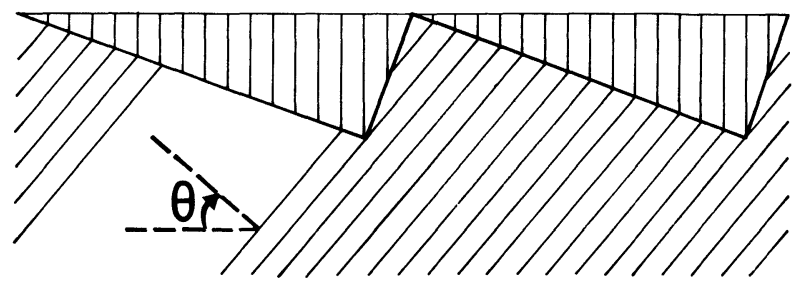

1c)

FIG. 1. - a) Typical aspect of a M24 planar sample above threshold, between crossed polarizers. The arrow indicates the direction of orientation of the molecules on the glass plates $\mathbf{n}_{0}$; magnifcation : $\times 200 . V / V_{\text {th }}=1.05, T_{\mathrm{SN}}-T=5 \times 10^{-1}{ }^{\circ} \mathrm{C}$. $b$ ) Typical aspect of a 40.8 homeotropic sample, above threshold, between crossed polarizers. $V=65 \mathrm{~V}, T_{\mathrm{SN}}-T=5 \times 10^{-1}{ }^{\circ} \mathrm{C}$ magnification : $\times 32$. Notice that, in the center of the rings, the molecules stay normal to the glass plate, in the same way as for umbilics in nematics. c) Schematic representation of the grain boundary near one of the plates. $\theta$ is the angle between the molecules in the middle of the slab and $\mathbf{n}_{0}$. 
in nematics [10]. In both cases $\left(\varepsilon_{\mathrm{a}} \gtrless 0\right)$, the period is small (a few microns), and decreases with increasing field and decreasing temperature. The analogy with the shear experiment induces us to interpret our pattern as a periodic array of grouped dislocation lines, or as the topologically equivalent regular array of grain boundaries schematically presented on figure $1 c$, generalizing an idea of Parodi [4].

Several characteristic features of these transitions are in marked contrast with what happens in nematics :

3.1 THE THRESHOLD FIELD IS PROPORTIONAL TO $d^{-1 / 2}$. - as shown in figure 2 , in agreement with ref. [4], while it varies as $d^{-1}$ for a Freedericksz' transition in a nematic.

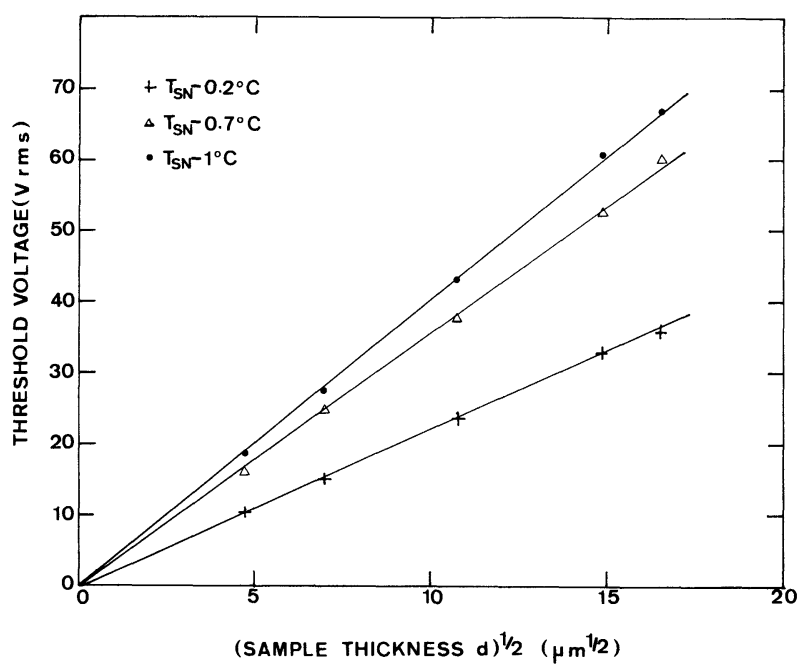

Fig. 2. - Dependence of the threshold voltage $V_{\text {th }}$ versus sample thickness $d$, for M24, for different temperatures. The $d^{1 / 2}$ behaviour predicted by reference [4] is well observed.

3.2 ThE DISTORTION STARTS WITH A FINITE AMPLITUDE, whereas it increases continuously from zero (second order transition) in the Freedericksz' case.

The tilt angle of the molecules can be deduced from the following observations : when the lines have formed, they are sometimes locally relaxed by small focal conics. The presence of these focal conic textures allows one to determine the angle $\theta$ between the direction $\mathbf{n}$ of the molecules in the midplane of the slab, and $\mathbf{n}_{0}$ : far from the ellipse, the smectic layers are normal to the hyperbola, and the excentricity of the ellipse is directly related to $\theta$, as shown by $\mathrm{C}$. Williams [11]. The evolution of $\theta$ versus applied voltage is reported in figure 3 : the distorsion starts with a non-zero value $\theta_{c}$, and increases up to $90^{\circ}$ for high fields. In the case of $\varepsilon_{\mathrm{a}}>0$ compounds, we have indeed obtained the typical conoscopic pattern of an homeotropic sample in that high field limit; the lines then completely disappear. In the case of negative $\varepsilon_{\mathrm{a}}$ compounds, we have not been able to reach the planar configuration, the required field being too large, because of the low $\varepsilon_{\mathrm{a}}$ value.

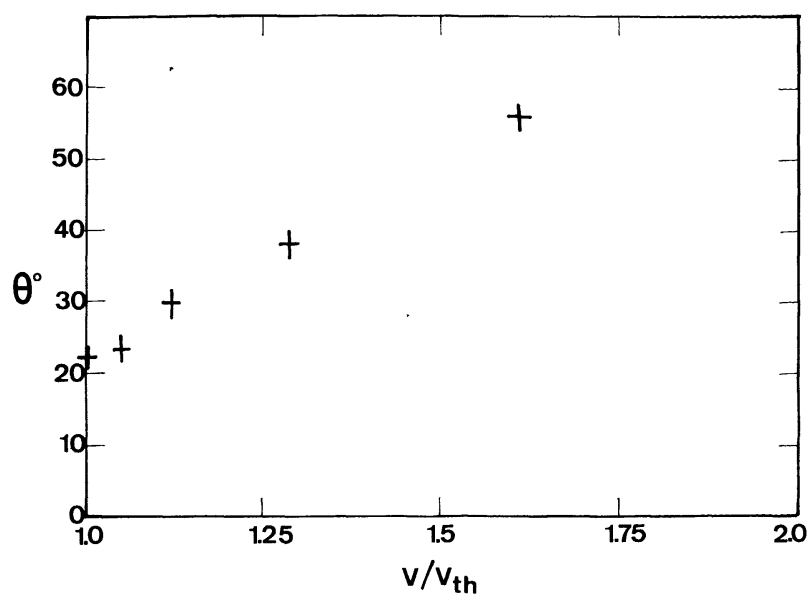

Fig. 3. - Dependence of the tilt angle of the molecules $\theta$ versus reduced voltage $V / V_{\text {th }}$. M24 sample, $d=100 \mu \mathrm{m}, T_{\mathrm{SN}}-T=3.3^{\circ} \mathrm{C}$.

From the tilt angle at threshold $\theta_{\mathrm{c}}$, we can evaluate the energy of the grain boundary $E_{\mathrm{g}}$ : the gain of electrical energy when the middle of the slab tilts to $\theta_{c}$ balances the energy of nucleation of the defects. In an elementary volume of $d \times 1 \mathrm{~cm}^{2}$ this gives :

$$
\frac{1}{2} \frac{\varepsilon_{\mathrm{a}}}{4 \pi} \int_{0}^{d}(\mathbf{E} \cdot \mathbf{n})^{2} \mathrm{~d} l=2 E_{\mathrm{g}} \frac{1}{\lambda}
$$

where $\lambda$ is the period of the array of defects.

This lead to :

$$
E_{\mathrm{g}}=\frac{\varepsilon_{\mathrm{a}}}{16 \pi} \frac{V_{\mathrm{th}}^{2}}{d} \lambda \sin ^{2} \theta_{\mathrm{c}}
$$

$E_{\mathrm{g}}=6 \times 10^{-6} \mathrm{erg} / \mathrm{cm}$ for $T_{\mathrm{SN}}-0.5^{\circ} \mathrm{C}$ and $E_{\mathrm{g}}=2 \times 10^{-5} \mathrm{erg} / \mathrm{cm}$ for $T_{\mathrm{SN}}-3^{\circ} \mathrm{C}$ in the case of $\mathrm{M} 24$.

We also mention that $\theta_{\mathrm{c}}$ decreases as the temperature is increased up to $T_{\mathrm{SN}}$ : this should, in principle, give a measure of the temperature dependence of $\bar{B}\left({ }^{3}\right)$.

We must emphasize that, contrary to what was usually thought, a field can act on the orientation of smectic A samples, even several degrees below the nematic to smectic A transition temperature $T_{\mathrm{SN}}$.

Another, and more practical interest of those transitions in smectic A compounds is that, if we remove the field after the distortion has occurred, the regular array of lines breaks down to form a texture of small focal conics, which scatters the light. These scattering domains remain stable in time, and can only be erased by heating the sample above $T_{\mathrm{SN}}$. This leads to an interesting storage mode which will be described in a forthcoming paper.

4. Pretransitional regime of distortion. - Very close to $T_{\mathrm{SN}}$, the Parodi type transition is replaced

$\left({ }^{3}\right)$ Dubois-Violette, E. and Williams, C. E., private communication. 
by the completely different regime of distortion shown in the left part of figure 4.

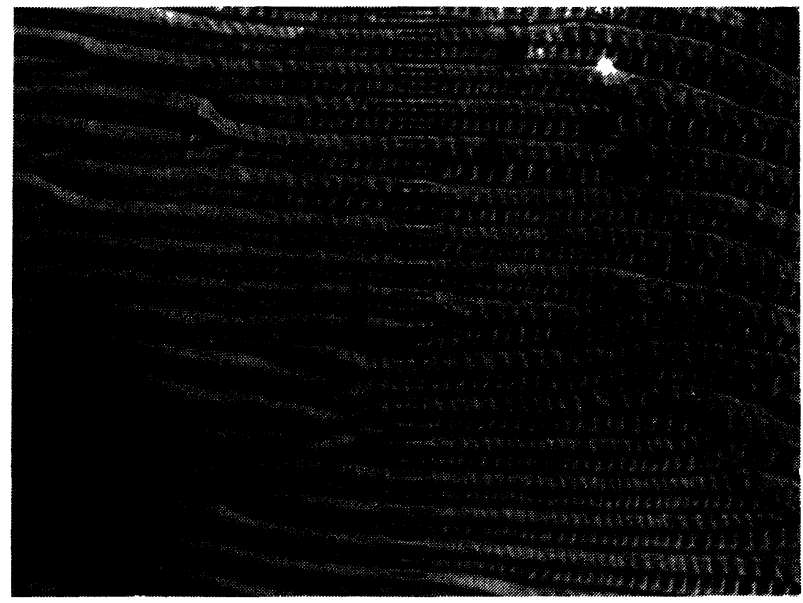

FIG. 4. - Pretransitional regime of distortion in a M24 planar sample. The stripes are parallel to $\mathbf{n}_{0}$. The right part corresponds to the completely smectic region of the sample.

The main features are the following :

- Above threshold, a regular pattern appears, but the stripes are now focal lines parallel to $\mathbf{n}_{0}$ (parallel to the plane ( $\mathbf{n}, \mathbf{n}_{0}$ ) in the homeotropic case). They are not visible with incoming light normal to $\mathbf{n}_{\mathbf{0}}$. The distortion is reversible : that is, it disappears if the field is decreased under threshold.

- This regime exists only in a very narrow temperature range (a few $10^{-2}$ degrees) close to $T_{\mathrm{SN}}\left(^{4}\right.$ ). The amplitude of that temperature range depends on the thermal gradients experienced by the sample.

$\left({ }^{4}\right)$ Experimentally, we identify $T_{\mathrm{SN}}$ to be the temperature for which, in zero field, a slight change in contrast is visible (for planar samples) between crossed polarizers, with incoming light parallel to $\mathbf{n}_{0}$. In the case of lateral + vertical temperature gradients, the blackest region corresponds to the completely smectic part of the sample.
- By varying the amplitude of the vertical and lateral gradients in the oven, we have been able to vary the slope of the nematic-smectic A interface in the sample, and to observe that the stripes are localized on that interface (they dive in the sample, in the same way as the interface). The presence of the interface is necessary to obtain the stripes, and we can completely suppress this regime for a nearly vertical interface.

- The period is very sensitive to the applied field.

- If the temperature is decreased after the stripes have been formed, the nematic-smectic A interface moves towards the nematic region, and in the completely smectic part, the stripes break down to give the aesthetic pattern of the right part of figure 4 .

Up to now, we have not been able to explain this second regime of distortion, which has yet been observed by P. E. Cladis [12], but we have established the necessity of the nematic-smectic $A$ interface to obtain it.

The precedingly described transitions are of course independent of the nature of the applied field, and the same phenomena have been observed in a $40.8100 \mu \mathrm{m}$ sample submitted to a $11 \rightarrow 15 \mathrm{kG}$ magnetic field.

5. Conclusion. - We have observed field induced transitions of the molecular orientation in several smectic A compounds. Contrary to what was usually thought, one can achieve field realignment of smectics A. Except in a narrow pretransitional temperature range $\left(\sim 10^{-2}{ }^{\circ} \mathrm{C}\right)$, the transition to a distorted molecular orientation is rendered possible by the nucleation of periodic arrays of defects. This transition is quite different from a Freedericksz' one : the threshold field varies as $d^{-1 / 2}$ and the distortion has a non-zero amplitude at threshold. Above threshold, the tilt angle of the molecules in the mid-plane of the sample increases continuously with increasing field, until a complete alignment by the field is obtained.

\section{References}

[1] Freedericksz, V. K. and Zolina, V., Trans. Faraday Soc. 29 (1933) 919.

[2] De Gennes, P. G., The Physics of Liquid Crystals (Oxford Press) 1974 , p. 291.

[3] Rapini, A., J. Physique 33 (1972) 237.

[4] Parodi, O., Solid State Commun. 11 (1972) 1503.

[5] K24 and M24 were purchased from BDH (England) and CBOOA from Eastman Kodak ; 40.8 was synthetized by Drs L. Liébert and Stzrelecki (Faculté des Sciences, Orsay).

[6] Rondelez, F., Thesis (Orsay) 1973.
[7] JANNING, J. L., Appl. Phys. Lett. 21 (1972) 173.

[8] Proust, J. E., Ter-Minassian-Saraga, L. and Guyon, E. Solid State Commun. 11 (1972) 1227.

[9] Williams, C. E. and Kleman, M., J. Physique Colloq. 36 (1975) C1-315.

[10] Rapini, A., Leger, L. and Martinet, A., J. Physique Colloq. 36 (1975) C1-189.

[11] Williams, C. E. and Kleman, M., J. Physique Lett. 35 (1974) L-33.

[12] Cladis, P. E. and Torza, S., J. Appl. Phys. 46 (1975) 584. 